Pupin T. I. Influence of fat-free, fat and sucrose diets on rat periodont condition. Journal of Education, Health and Sport. 2021;11(05): 179-184. eISSN 2391-8306. DOI http://dx.doi.org/10.12775/JEHS.2021.11.05.018

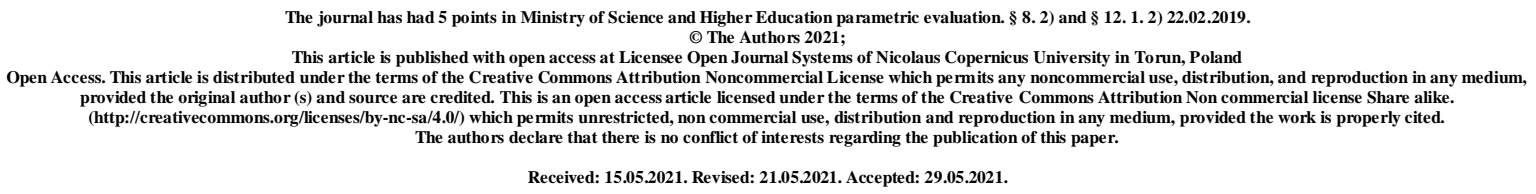

UDK 616.314:664.315

\title{
INFLUENCE OF FAT-FREE, FAT AND SUCROSE DIETS ON RAT PERIODONT CONDITION
}

\author{
T. I. Pupin
}

\section{Lviv National Medical University named after Danylo Galytskij}

\begin{abstract}
Aim. To investigate the effect of consumption of diets with different content of fat and sugar on the state of the periodontium of rats.

Methods. The rats received a semi-synthetic fat-free diet (FFD), a fat diet (5\% sunflower oil), and a sucrose diet (50\% sucrose) for 30 days. Determined the degree of periodontal atrophy, tooth decay and in the gum homogenate - the activity of elastase, catalase, urease, lysozyme and the content of malondialdehyde (MDA).

Results. Sugar diet increases the degree of periodontal atrophy and tooth decay, but decreases elastase activity in the gums and increases catalase activity. Fat diet does not affect periodontal atrophy and tooth decay, but it reduces catalase activity.

Conclusion. The increase in the intensity of caries and periodontal atrophy under the influence of a sucrose diet is probably due to the stimulation of the formation of lactic acid. Fat nutrition does not affect the intensity of dental caries and the degree of periodontal atrophy.
\end{abstract}

Key words: nutrition; periodontium; inflammation; antioxidant protection. 


\section{Introduction}

The role of alimentary factors in the development of periodontal pathology has long been seen [1]. It's not up to the end of the periodontogenic fusion of specific alimentary factors.

Recently, there have been reports of periodontopathogenic effects of consuming fats high in palmitic acid [2]. However, data on the effect on the periodontium of the most widely used sunflower oil in Ukraine is contradictory. Thus, according to some studies, it does not adversely affect the condition of the periodontium [2], according to others - increases the degree of periodontal atrophy [3]. To date, there is no convincing information about the effects on the periodontium of a sucrose diet, which is widely used to reproduce dental caries [4].

Therefore, the aim of this study was to investigate the effect on the periodontal condition of rats of consuming diets with different fat and sucrose content, namely: semisynthetic fat diet, diet with 5\% sunflower oil and diet with $50 \%$ sucrose.

\section{Material and research methods}

The experiments were performed on 18 white Wistar rats (males, 5 months, 224-232 g), divided into 3 groups: 1-a received a fat-free diet (FFD), the composition of which is shown in table 1, 2-a received a fat diet with content of $5 \%$ sunflower oil (instead of $5 \%$ starch) and the 3rd received a sucrose diet with a content of $50 \%$ sucrose (instead of $50 \%$ starch). The duration of feeding was 30 days. After euthanasia under thiopental anesthesia (20 mg/kg), gums were isolated, in the homogenate of which the activity of elastase [5], catalase [5], urease [6], lysozyme [6] and malonic dialdehyde (MDA) content were determined [5].

Table 1. The composition of rations (\%) for rats [5]

\begin{tabular}{|l|c|c|c|}
\hline \multicolumn{1}{|c|}{ Components } & $\begin{array}{c}\text { Fat-free diet } \\
\text { (FFD) }\end{array}$ & $\begin{array}{c}\text { Fat diet (5\% } \\
\text { sunflower oil) }\end{array}$ & $\begin{array}{c}\text { Sucrose diet } \\
\text { (50\% sucrose) }\end{array}$ \\
\hline Cornstarch & 65 & 60 & 19 \\
\hline Soybean meal is defatted & 20 & 20 & 20 \\
\hline Ovalbumin & 6 & 6 & 6 \\
\hline Sucrose & 4 & 4 & 50 \\
\hline Sunflower oil & 0 & 5 & 0 \\
\hline Mineral mixture & 4 & 4 & 4 \\
\hline Vitamin mixture & 1 & 1 & 1 \\
\hline
\end{tabular}


According to the ratio of catalase activity and MDA content, the antioxidantprooxidant index of API was calculated [5].

The degree of periodontal atrophy and dental caries was determined in accordance with the recommendations [7].

The results of the experiments were subjected to standard statistical processing [8-10].

\section{Results and discussion}

Table 2 presents the results of determination in the gums of the level of markers of inflammation, namely the activity of the proteolytic enzyme elastase and the content of the final product of lipid peroxidation of malonic dialdehyde (MDA). As can be seen from these data, the consumption of sucrose diet reduces the activity of elastase by $35 \%$ (compared to the group "FFD"), while the fatty diet tends to increase the level of elastase (10\%) and MDA $(22 \%)$.

Table 2. The effect of nutrition on the level of markers of inflammation in the gums of rats

\begin{tabular}{|c|l|c|c|}
\hline №№ & \multicolumn{1}{|c|}{ Groups } & Elastase, $\mu$-cat / kg & MDA, mmol / kg \\
\hline 1 & FFD & $49 \pm 2$ & $12,0 \pm 1,1$ \\
\hline 2 & Fat diet & $54 \pm 3$ & $14,6 \pm 1,6$ \\
& & $\mathrm{p}>0,05$ & $\mathrm{p}>0,05$ \\
\hline 3 & Sucrose diet & $32 \pm 4$ & $12,7 \pm 0,2$ \\
& & $\mathrm{p}<0,01$ & $\mathrm{p}>0,05$ \\
& & $\mathrm{p}_{1}<0,01$ & $\mathrm{p}_{1}>0,05$ \\
\hline
\end{tabular}

Notes: $\mathrm{p}$ - in comparison with group 1; p1 - in comparison with group 2.

Table 3 presents the results of determining in the gums the activity of the antioxidant enzyme catalase and the API index. It is seen that a fatty diet reduces the activity of catalase by $27 \%$ and the API index by $40 \%$. Sucrose diet, in contrast, increases the activity of catalase by $29 \%$ and the API index by $22 \%$.

Table 3. Effect of nutrition on catalase activity and API index in rat gums

\begin{tabular}{|c|l|c|c|}
\hline №№ & \multicolumn{1}{|c|}{ Groups } & Catalase, mcat / kg & API \\
\hline 1 & FFD & $6,32 \pm 0,42$ & $5,27 \pm 0,35$ \\
\hline 2 & Fat diet & $4,61 \pm 0,41$ & $3,16 \pm 0,24$ \\
& & $\mathrm{p}<0,05$ & $\mathrm{p}<0,01$ \\
\hline 3 & Sucrose diet & $8,16 \pm 0,23$ & $6,42 \pm 0,40$ \\
& & $\mathrm{p}<0,05$ & $\mathrm{p}<0,05$ \\
& & $\mathrm{p}_{1}<0,01$ & $\mathrm{p}_{1}<0,01$ \\
\hline
\end{tabular}

Notes: see table 2. 
Table 4 presents the results of determining in the gums the activity of the bacterial enzyme urease and the antimicrobial enzyme lysozyme. It is seen that fatty and sucrose diets show only a tendency to decrease the activity of urease and to increase the activity of lysozyme.

Table 4. The effect of nutrition on the activity of urease and lysozyme in the gums of rats

\begin{tabular}{|c|l|c|c|}
\hline №oo & Groups & Urease, mcat / kg & Lysozyme, units / kg \\
\hline 1 & FFD & $3,04 \pm 0,55$ & $178 \pm 31$ \\
\hline 2 & Fat diet & $2,74 \pm 0,34$ & $181 \pm 17$ \\
& & $\mathrm{p}>0,3$ & $\mathrm{p}>0,6$ \\
\hline 3 & Sucrose diet & $2,72 \pm 0,22$ & $225 \pm 19$ \\
& & $\mathrm{p}>0,3$ & $\mathrm{p}>0,05$ \\
& & $\mathrm{p}_{1}>0,8$ & $\mathrm{p}_{1}>0,05$ \\
\hline
\end{tabular}

Notes: see table 2.

Table 5 presents the results of determining the degree of periodontal atrophy and dental caries. It is seen that a significant increase in the degree of periodontal atrophy is observed in rats receiving a sucrose diet. It is in rats of this group that the number of carious lesions increases significantly.

Table 5. The effect of nutrition on the degree of atrophy of the alveolar process and dental caries

\begin{tabular}{|c|l|c|c|}
\hline №oo & Groups & $\begin{array}{c}\text { The degree of } \\
\text { periodontal } \\
\text { atrophy, } \%\end{array}$ & $\begin{array}{c}\text { Quantity of carious } \\
\text { lesions per 1 rat }\end{array}$ \\
\hline 1 & FFD & $21,4 \pm 1,1$ & $4,3 \pm 0,1$ \\
\hline 2 & Fat diet & $23,2 \pm 1,8$ & $4,5 \pm 0,2$ \\
& & $\mathrm{p}>0,3$ & $\mathrm{p}>0,05$ \\
\hline 3 & Sucrose diet & $26,7 \pm 2,0$ & $5,8 \pm 0,3$ \\
& & $\mathrm{p}<0,05$ & $\mathrm{p}<0,01$ \\
& $\mathrm{p}_{1}>0,05$ & $\mathrm{p}_{1}<0,01$ \\
\hline
\end{tabular}

Notes: see table 2.

Our data suggest that the sucrose diet not only contributes to the development of dental caries, but also provokes periodontal atrophy. The question is why in rats fed a sucrose diet, elastase activity does not increase, but increases catalase activity and API index? It is possible that the negative effect of the sucrose diet on the state of the periodontium is explained by the ability of sucrose to stimulate the formation of lactic acid, which dissolves not only the enamel of the teeth, but also the bone tissue of the periodontium. 


\section{Conclusions}

1. Sucrose diet reduces the level of inflammation and increases antioxidant and antimicrobial protection in the periodontium.

2. Sucrose diet increases not only the impact of dental caries, but also the degree of periodontal atrophy.

3. A fatty diet reduces the antioxidant protection of the periodontium by reducing the activity of the enzyme catalase, but does not significantly affect the condition of the teeth and periodontium.

\section{References}

1. Levitsky AP. Alimentary factors in the pathogenesis, prevention and treatment of dental diseases. Dentistry Bulletin. 2005;2:5-7. (in Russian)

2. Markov AV. Influence of high-fat diets with different fatty acid composition on rat periodontal condition. Journal Education, Health and Sport. 2017;7(1):846-856.

3. Levitsky AP, Makarenko OA, Selivanskaya IA [and others]. The application of high olein sunflower oil "Olivka" for the prevention of noninfectious diseases: the guidelines. Odessa, KP OGT, 2016:16. (in Russian)

4. Levitsky AP, Denga OV, Ivanov VS [and others]. The experimental stomatology. P. I. The experimental models of stomatological diseases. Odessa, KP OGT, 2017:59-67. (in Russian)

5. Levitsky AP, Makarenko OA, Demyanenko SA. Methods of experimental dentistry (teaching aid). Simferopol, Tarpan, 2018:78. (in Russian)

6. Levitsky AP, Makarenko OA, Selivanskaya IA. [and others]. Enzymatic methods for determination of oral dysbiosis for screening pro- and prebiotics: method guidelines. Kiev, GFC, 2007:22. (in Russian)

7. Shnayder SA, Levitsky AP. The experimental stomatology. P. I. The experimental models of stomatological diseases. Odessa, KP OGT, 2017:168. (in Russian)

8. Truhacheva NV. Mathematical Statistics in biomedical research using application package Statistica. Moskow, GJeOTAR-Media, 2012:379. (in Russian)

9. Gozhenko A. I., Levitsky A. P., Stepan V. T., Pustovoit I. P., Badiuk N. S., Maslyukov A. K. Advantages of high olein sunflower oil over palm oil according to biochemical research results / - PhOL - PharmacologyOnLine - N 2. - P. 293-301. https://pharmacologyonline.silae.it/files/archives/2020/vol2/PhOL 20202 A028 Gozhenko. pdf 
10. Levitsky A. P., Egorov B. V., Gozhenko A. I., Badiuk N.S., Selivanskaya I. A., Lapinskaya A. P. Influence of high-fat nutrition with different fat-acid composition of fats on lipid peroxidation processes in rat's organs and tissues / PharmacologyOnLine; Archives 2021 - vol.1. $\quad-\quad$ P. https://pharmacologyonline.silae.it/files/archives/2021/vol1/PhOL 20211 A006 Levitsky.p df 